\title{
Analysis on Wearable Antenna Performance on Different Radiating Elements for GPS Application
}

\author{
M.S. Amin Nordin ${ }^{1 *}$, N.H. Abd Rahman ${ }^{1,2}$, M.T. Ali ${ }^{1}$, N.I. Zaidi ${ }^{1}$, M. R. Ahmad ${ }^{3}$ \\ ${ }^{1}$ Faculty of Electrical Engineering, \\ Universiti Teknologi MARA, Shah Alam, Selangor, 40450, MALAYSIA \\ ${ }^{2}$ Malaysia-Japan International Institute of Technology, \\ Universiti Teknologi Malaysia, Jalan Sultan Yahya Petra, Kuala Lumpur, 54100, MALAYSIA \\ ${ }^{3}$ Faculty of Applied Science, \\ Universiti Teknologi MARA, Shah Alam, Selangor, 40450, MALAYSIA \\ *Corresponding Author
}

DOI: https://doi.org/10.30880/ijie.2020.12.06.005

Received 10 August 2019; Accepted 29 May 2020; Available online 02 July 2020

\begin{abstract}
This paper presents a study on the performance of self-manufactured electro-textile (SME-T) antenna that was designed at $1.575 \mathrm{GHz}$ based on the allocated spectrum for Global Positioning System (GPS) application. However, due to its known low-conductivity characteristic, the ability of the newly developed material to perform as a good antenna shall be verified. Therefore, the performance of the antennas are compared and studied with respect to established materials such as adhesive copper tape and commercial conductive fabric named SHIELDIT ${ }^{\mathrm{TM}}$ as the radiating elements. Here, four e-textile antennas having approximately the same size are fabricated and tested. The performance of all antennas, in terms of return loss, radiation pattern, gain, and efficiency; manufactured by using different radiating elements, such as copper, SHIELDIT ${ }^{\mathrm{TM}}$ and SME-T fabricated on polyester fabric as the substrate are analyzed. The measured return loss and radiation pattern of SME-T antenna has proven that the antenna is well suited for wearable application. The measured antenna gain and efficiency of $0.61 \mathrm{~dB}$ and $25.95 \%$ are obtained and it is proven that the fabricated SME-T antenna can act as a receiving antenna designed for GPS applications which requires low gain antenna for passive monitoring.
\end{abstract}

Keywords: Electro-textile, GPS, textile antenna, wearable antenna

\section{Introduction}

Wearable antennas for body area network especially electro-textile antenna had gathered much intention recently. Electro textile enables digital and electronic device to be embedded into garment and increases the invisibility of wearable antenna. The conventional antenna is not relevant anymore for the current wearable technology as it is rigid and too bulky for wearable application [1,2]. However, electro-textile antennas consist of a textile conductive element integrated with another textile material acting as substrate and have the advantage of being lightweight and flexible $[3,4]$.

Most manufacturing works on wearable antennas employed normal fabrics integrated with copper-based radiating elements such as copper tape, copper foil or copper powder, which can lead to significant performance degradation during measurement [5]. This have caused a huge disadvantage which lead to the sustainability issue, where the antenna can be easily detached from the fabric after being washed or worn for many times [6]. Due to this issue, the authors have recently developed a more stable electro-textile fabric, which is more structurally rigid and strong, which has been done in this paper by constructing the polyester and copper thread together [7]. 
In order to prove that this new electro-textile material can perform as a good antenna, detailed study was carried out based on the comparison analysis of various radiating elements such as adhesive copper tape, SHIELDIT ${ }^{\mathrm{TM}}$ and SME-T. Here, polyester has been chosen as the antenna substrate due to its wrinkle-resistant property and resilient ability. Results were obtained from network analyzer and anechoic chamber measurements and compared with simulation results.

\section{Antenna Structure}

For the implementation of the proposed e-textile antenna, a microstrip square patch probe-fed antenna was chosen and polyester with dielectric constant of 1.36 and loss tangent of 0.031 is selected as a substrate of the antenna. These antennas are appropriate to use on textile material, because they present a simple geometry, which makes them easier to fabricate. In the fabrication of textile antenna, four e-textile antennas of the approximately same size are fabricated to ensure the validity of the analysis under controlled parameters. As for the radiating element, adhesive copper tape, SHIELDIT $^{\mathrm{TM}}$, or SME-T was used. The antenna was designed by using CST Studio Suite software at $1.575 \mathrm{GHz}$ resonant frequency.

Here, in this paper, due to the complexity and inhomogeneous structure of electro-textile, the modelling of conductive element in textile antenna in simulation is simplified in terms of its bulk conductivity, $\sigma$. The conductivity of SME-T is $\sigma\left(\approx 3.02 \times 10^{4}\right) \mathrm{S} / \mathrm{m}$ and the conductivity of SHIELDITTM is $\sigma\left(\approx 1.18 \times 10^{5}\right) \mathrm{S} / \mathrm{m}$ [8]. Both conductive elements are compared with an established materials adhesive copper tape that has conductivity of $\sigma\left(\sim 10^{7}\right) \mathrm{S} / \mathrm{m}[8]$. This commercialized conductive textile has a layer of adhesive tape on its reverse side, which can be used to secure it onto the polyester substrate. This is performed by heating and attaching the material by using hot compressor. In this work, the overall structure is fabricated using manual cutting tools.

Table1 shows the fabricated antennas parameters, designed by using different radiating elements, with full ground plane at the back. In order to prove that this new electro-textile material can be used as antenna, E-textile 1 is formed by fabricating the SME-T at the front (patch) and copper tape as the ground while for E-textile 2; both sides are using the SME-T. Fig. 1 shows the fabricated antennas using commercialized conductive elements, while Fig. 2 shows SME-T antenna.

a

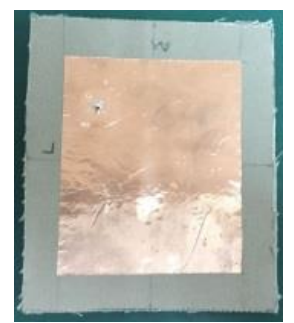

b

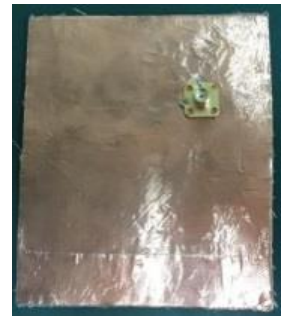

c

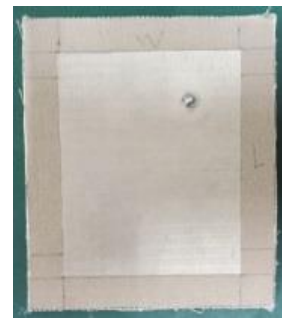

d

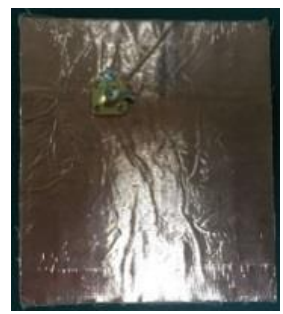

Fig. 1 - (a) copper tape (front)

(c) SHIELDIT ${ }^{\mathrm{TM}}$ (front);

(d) copper tape (back)

a

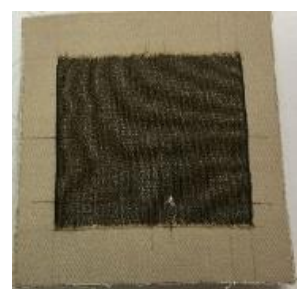

b

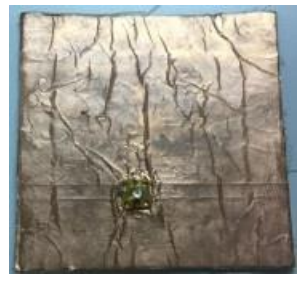

c

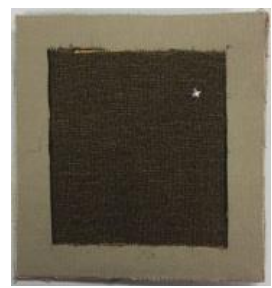

d

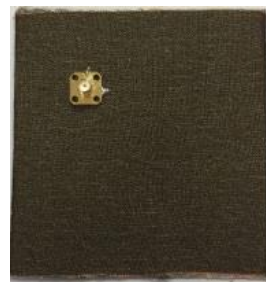

Fig. 2 - (a) E-textile 1(front); (b) copper tape (back); (c) E-textile 2(front); (d) E-textile 2 (back) 
Table 1 - Design parameters of e-textile antenna

\begin{tabular}{lcccc}
\hline \multirow{2}{*}{$\begin{array}{c}\text { Type of Radiating } \\
\text { Elements (Patch }\end{array}$} & \multicolumn{3}{c}{ Parameters for radiating elements of textile antennas } \\
\cline { 2 - 5 } & $\begin{array}{c}\text { Length } \\
\text { patch }(\boldsymbol{L p})\end{array}$ & $\begin{array}{c}\text { Width } \\
\text { patch }(\boldsymbol{W p})\end{array}$ & $\begin{array}{c}\text { Thickness } \\
\text { patch }(\boldsymbol{t} \boldsymbol{p})\end{array}$ & $\begin{array}{c}\text { Conductivity } \\
\text { of RE, } \boldsymbol{\sigma}\end{array}$ \\
\hline Copper tape & $78.4 \mathrm{~mm}$ & $65 \mathrm{~mm}$ & $0.035 \mathrm{~mm}$ & $2.91 \times 10^{7} \mathrm{~S} / \mathrm{m}$ \\
SHIELDIT ${ }^{\mathrm{TM}}$ & $78.7 \mathrm{~mm}$ & $66 \mathrm{~mm}$ & $0.11 \mathrm{~mm}$ & $1.33 \times 10^{5} \mathrm{~S} / \mathrm{m}$ \\
E-textile (1) & $78.8 \mathrm{~mm}$ & $67 \mathrm{~mm}$ & $0.48 \mathrm{~mm}$ & $3.02 \times 10^{4} \mathrm{~S} / \mathrm{m}$ \\
E-textile (2) & $79.0 \mathrm{~mm}$ & $74 \mathrm{~mm}$ & $0.48 \mathrm{~mm}$ & $3.02 \times 10^{4} \mathrm{~S} / \mathrm{m}$ \\
\hline
\end{tabular}

\section{Result and Discussion}

The simulated and measured return loss, $S_{11}$ is displayed in Fig. 3. The agreement considerably contributes to this very good result. Based on the figure, it can be seen that a good return loss has been obtained by the textile antenna using commercial conductive materials; copper tape and SHILEDIT ${ }^{\mathrm{TM}}$. However, there is a slight disagreement between the simulated and measured results may be due to fabrication tolerance in the process of attaching the materials by using hot compressor. This process can damage some of the materials by burning out the fabric when there is over pressing during the attaching process, thus it has degraded the antennas performance. Table 2 shows summary of the antenna return loss, $\mathrm{S}_{11}$ and bandwidth comparison between simulation and measurement result by using copper tape and SHIELDIT ${ }^{\mathrm{TM}}$.

a)

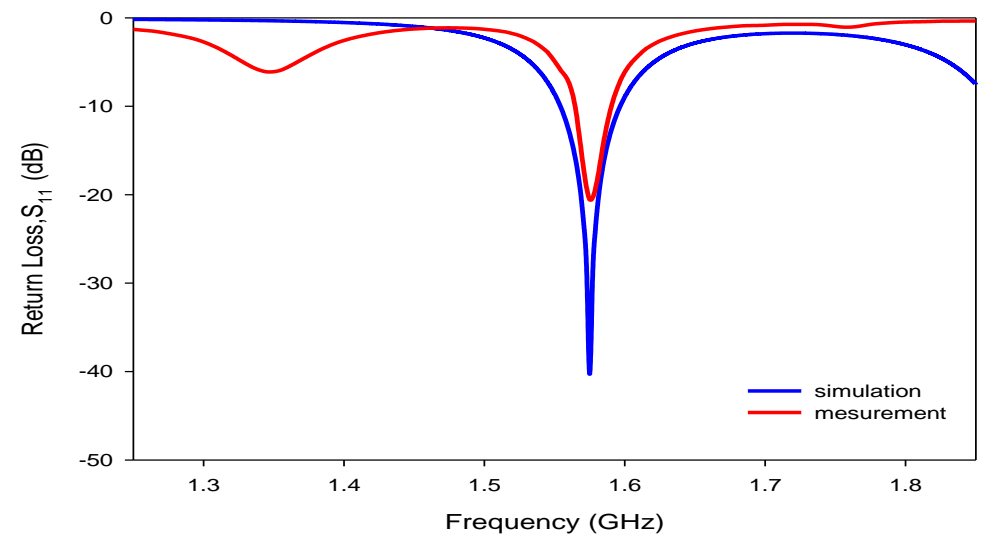

b)

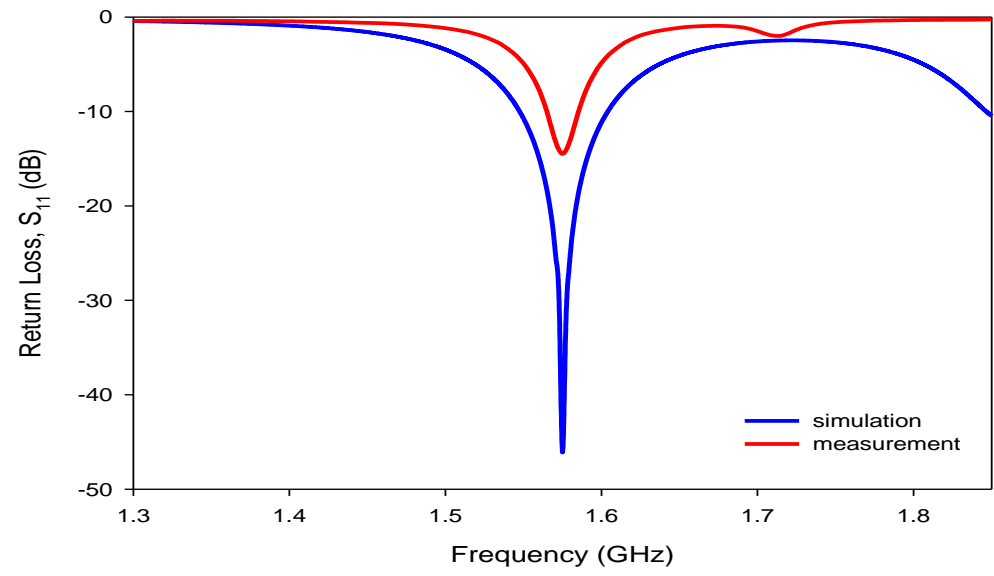

Fig. 3 - The simulated and measured return loss on antenna for: (a) Copper tape and (b) SHIELDIT ${ }^{\mathrm{TM}}$ 
Table 2 - S11 and bandwidth performance by using commercial conductive material

\begin{tabular}{cccc}
\hline Antenna & Parameters & Simulation & Measurement \\
\hline Copper tape & Return Loss, $\mathrm{S}_{11}$ & $-39.51 \mathrm{~dB} @ 1.575 \mathrm{GHZ}$ & $-20.71 \mathrm{~dB} @ 1.575 \mathrm{GHz}$ \\
& Bandwidth & $0.04 \mathrm{GHz}$ & $0.031 \mathrm{GHz}$ \\
& & & \\
SHIELDIT $^{\mathrm{TM}}$ & Return Loss, $\mathrm{S}_{11}$ & $-45.29 \mathrm{~dB} @ 1.575 \mathrm{GHz}$ & $-14.97 \mathrm{~dB} @ 1.575 \mathrm{GHz}$ \\
& Bandwidth & $0.054 \mathrm{GHz}$ & $0.02 \mathrm{GHz}$ \\
\hline
\end{tabular}

On the other hand, Fig. 4 shows the simulated and measured return loss, $\mathrm{S}_{11}$ of the proposed e-textile antenna. The agreement is almost perfect. The antenna considerably contributes to excellent result. It can be seen that a good agreement was acquired between fabricated and simulated antenna, but with slightly shifted in return loss on the measured antenna. These slight disagreements are mainly caused by the fabrication inaccuracies and the inhomogeneous material properties of the SME-T. Despite all that, this result is still acceptable as the $S_{11}$ is within the required band (GPS). Table 3 shows the antenna return loss, $\mathrm{S}_{11}$ and bandwidth comparison between simulation and measurement result by using SME-T.

a)

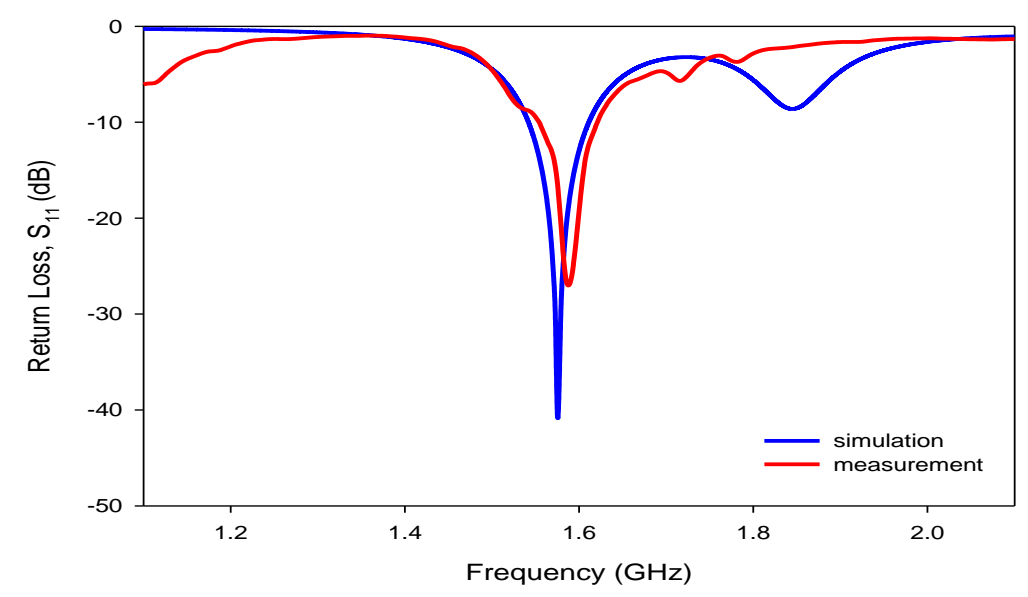

b)

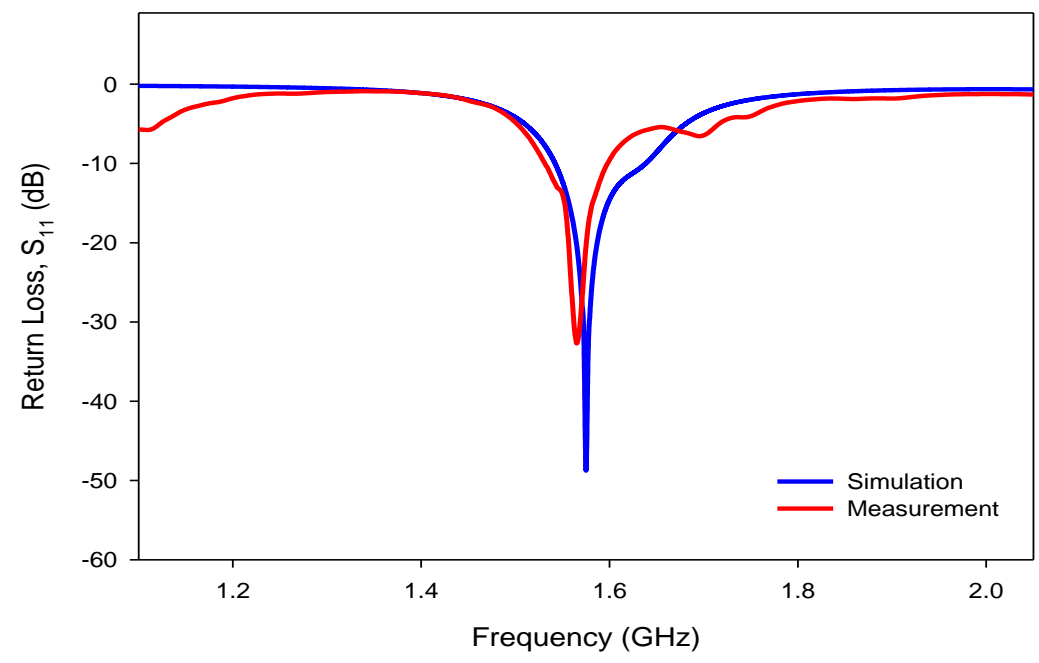

Fig. 4 - The simulated and measured return loss on antenna for: (a) E-textile 1 and (b) E-textile 2 
Table 3 - S11 and bandwidth performance of antenna by using SME-T

\begin{tabular}{cccc}
\hline Antenna & Parameters & Simulation & Measurement \\
\hline E-textile (1) & Return Loss, $\mathrm{S}_{11}$ & $-40.05 \mathrm{~dB} @ 1.575 \mathrm{GHz}$ & $-27.09 \mathrm{~dB} @ 1.581 \mathrm{GHz}$ \\
& Bandwidth & $0.073 \mathrm{GHz}$ & $0.07 \mathrm{GHz}$ \\
& & & \\
E-textile (2) & Return Loss, $\mathrm{S}_{11}$ & $-48.11 \mathrm{~dB} @ 1.575 \mathrm{GHz}$ & $-32.93 \mathrm{~dB} @ 1.566 \mathrm{GHz}$ \\
& Bandwidth & $0.094 \mathrm{GHz}$ & $0.068 \mathrm{GHz}$ \\
\hline
\end{tabular}

Table 4 shows the antenna performance based on the gain and radiation efficiency of textile antenna by using copper tape and SHILEDIT ${ }^{\mathrm{TM}}$. The gain, efficiency and radiation pattern measurement had been conducted through anechoic chamber. The model of anechoic chamber used is ATENLAB OTA-500, capable to measure the antenna performance such as efficiency and gain ranging from $600 \mathrm{MHz}$ up to $18 \mathrm{GHz}$. The gain and efficiency value were degraded in the measurement may be due to the high loss tangent, $(\tan \delta \approx 0.031)$ introduced by polyester layer. Despite that, Fig. 5 and Fig. 6 present a directional front lobe and minimum back lobe and that directly generated high directivity for both textile antennas between simulated and measured result. This proves the advantage of using coaxial probe feeding, where the $50 \Omega$ impedance matching point is accurate.

Table 4 - Gain and efficiency performance of antenna by using commercial conductive materials

\begin{tabular}{cccc}
\hline Antenna & Parameters & Simulation & Measurement \\
\hline Copper tape & Gain & $2.06 \mathrm{~dB}$ & $1.5 \mathrm{~dB}$ \\
& Efficiency & $34.21 \%$ & $31.53 \%$ \\
\multirow{2}{*}{ SHIELDIT TM } & Gain & $1.7 \mathrm{~dB}$ & $1.23 \mathrm{~dB}$ \\
& Efficiency & $32.18 \%$ & $29.03 \%$ \\
\hline
\end{tabular}

a

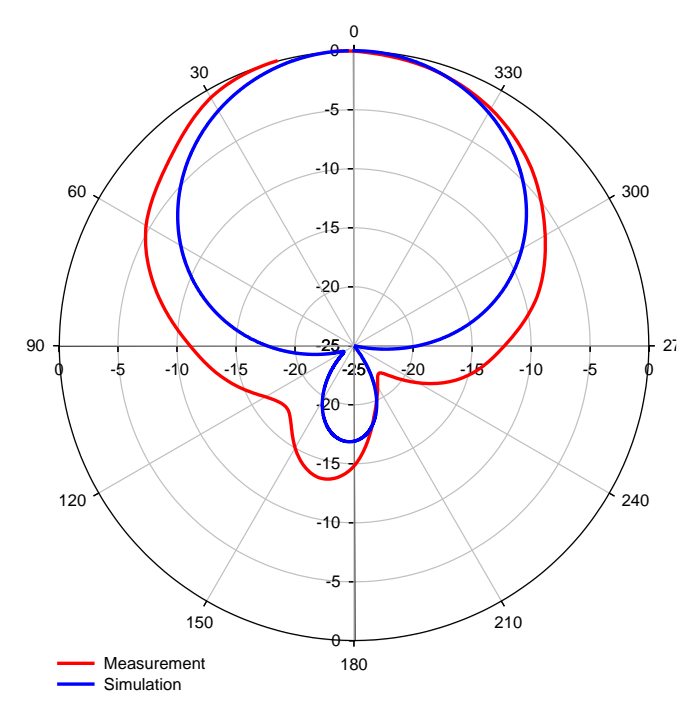

b

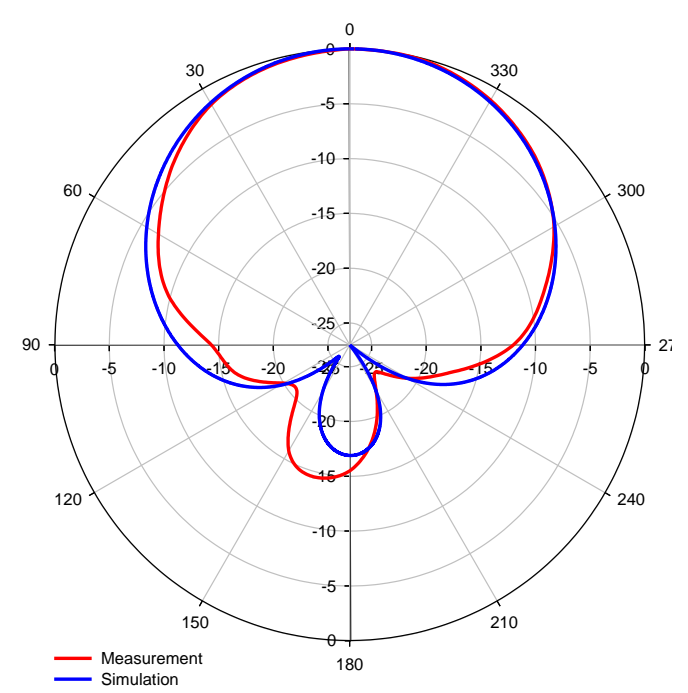

Fig. 5 - The simulated and measured radiation pattern on antenna for: (a) copper tape $\left(\right.$ phi $\left.=0^{\circ}\right)$; (b) copper tape $\left(\right.$ phi $\left.=90^{\circ}\right)$ 
a

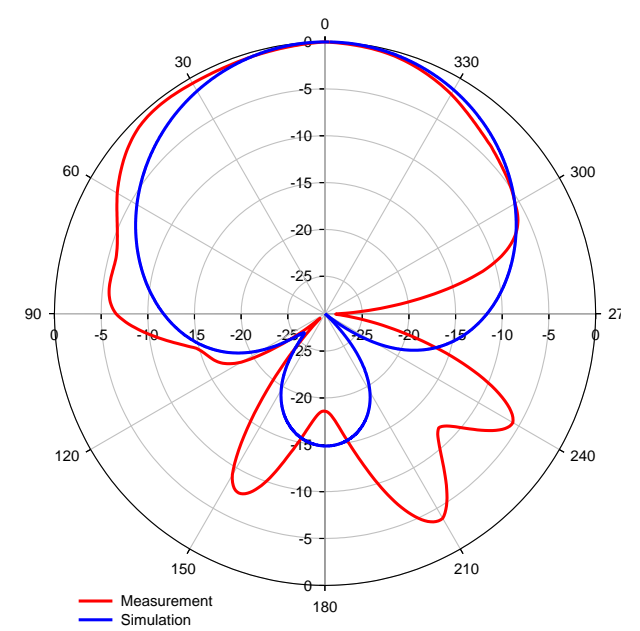

b

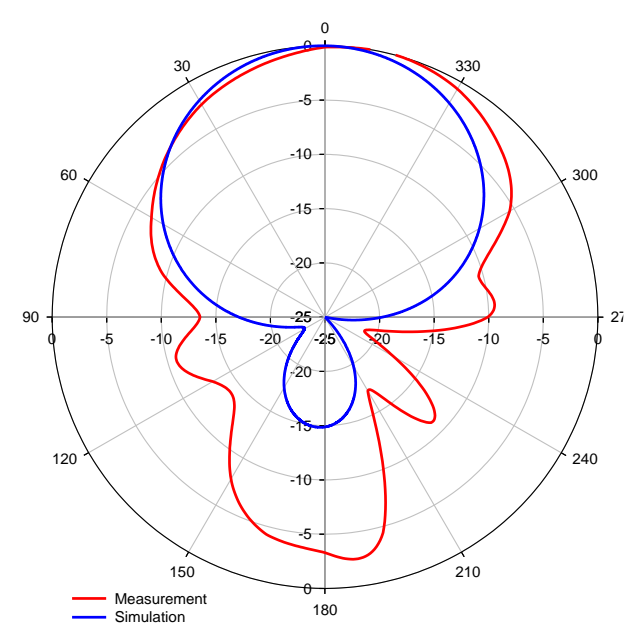

Fig. 6 - The simulated and measured radiation pattern on antenna for: (a) SHIEDIT $^{\mathrm{TM}}\left(\mathrm{phi}^{\circ} \mathbf{0}^{\circ}\right)$; (b) SHIEDIT $^{\mathrm{TM}}\left(\mathbf{p h i}=90^{\circ}\right)$

Based on Table 5, both SME-T antennas give acceptable performance but with a measured gain and efficiency value lower than the other two adhesive conductive radiating elements. It shows marginal disagreements between the simulated and measured results due to the inaccuracies in the fabrication process and probably due to the use of high loss tangent polyester substrate and it has degraded the efficiency. Other than that, the conduction losses and surface resistivity of the SME-T, with the lowest conductivity, $\sigma\left(3.02 \times 10^{4} \mathrm{~S} / \mathrm{m}\right)$, have slightly affected the performance of the antenna, as the other two commercial conductive materials, copper tape and SHIELDIT ${ }^{\mathrm{TM}}$ have better performance. Despite that, a stable radiation pattern is observed throughout the operating frequency band with high front-to-back ratio (FBR) radiation as shown in Fig. 7 and Fig. 8. This is advantageous for on-body communications. The higher cross polarization with high FBR radiation is caused mainly by coaxial probe feeding, which can behave as a receiving antenna designed for GPS application.

Table 5 - Gain and efficiency performance of antenna by using SME-T

\begin{tabular}{cccc}
\hline Antenna & Parameters & Simulation & Measurement \\
\hline \multirow{2}{*}{ E-textile (1) } & Gain & $1.4 \mathrm{~dB}$ & $0.86 \mathrm{~dB}$ \\
& Efficiency & $30.25 \%$ & $27.1 \%$ \\
E-textile (2) & Gain & $0.77 \mathrm{~dB}$ & $0.61 \mathrm{~dB}$ \\
& Efficiency & $28.68 \%$ & $25.95 \%$ \\
\hline
\end{tabular}


a

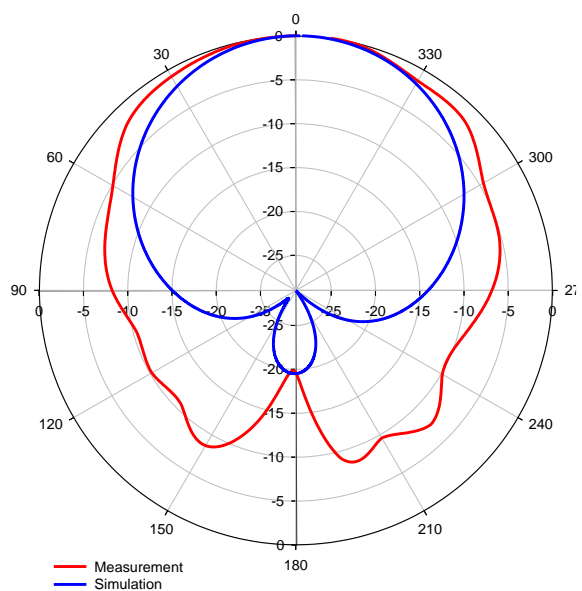

b

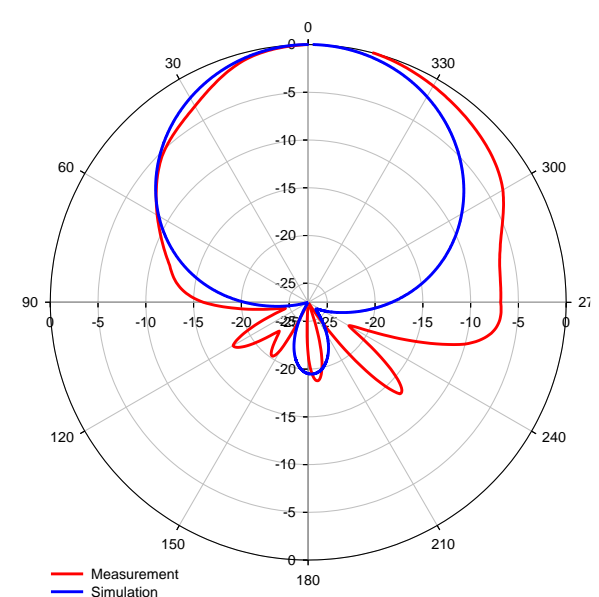

Fig. 7 - The simulated and measured radiation pattern on antenna for: (a) E-textile $1\left(\mathrm{phi}=0^{\circ}\right)$; (b) E-textile $1\left(\right.$ phi $\left.=90^{\circ}\right)$

a

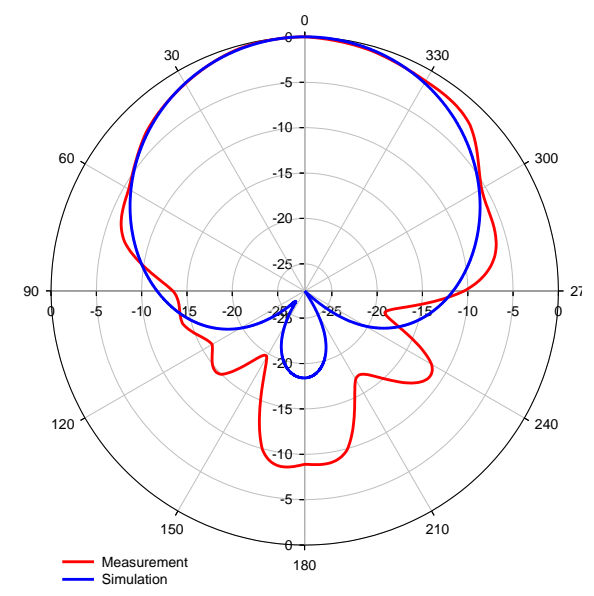

b

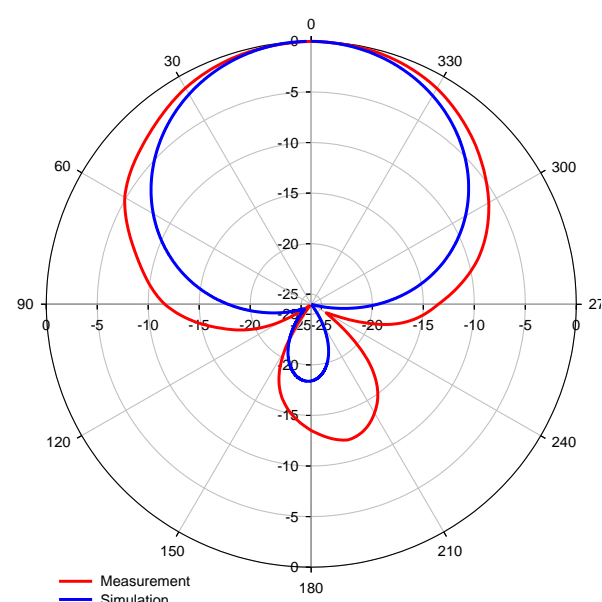

Fig. 8 - The simulated and measured radiation pattern on antenna for: (a) E-textile $2\left(\mathrm{phi}=0^{\circ}\right.$ ); (b) E-textile $2\left(\mathrm{phi}=90^{\circ}\right)$

Table 6 shows the summarized and comparison of the performances of the antennas using for different radiating elements. Based on the table, antenna with copper tape radiating element gives the best performances regarding to return loss, gain and efficiency compare to others antennas specifically with E-textile (2) antenna. This may due to the highest conductivity and stability of the copper tape material. Moreover, impedance mismatch loss was happened during the fabrication of all the antennas that had affected the degraded of gain and efficiency of the antennas. In [9] the antenna radiation efficiency, which is used to relate the gain and directivity has been proved that the polyester with low $\varepsilon_{\mathrm{r}}$ and tan $\delta$ has degraded the antenna gain and efficiency:

$$
G=e_{c d} \cdot D
$$

$$
\text { Where } \begin{aligned}
\mathrm{G} & =\text { Gain } \\
\mathrm{e}_{\mathrm{c}} & =\text { conduction efficiency } \\
, \mathrm{e}_{\mathrm{d}} & =\text { dielectric efficiency } \\
\mathrm{D} & =\text { Directivity }
\end{aligned}
$$

Despite that, the antenna using E-textile (2) also gives acceptable performances with good return loss and gain which have a potential to prove as the radiating material on the antenna GPS application. 
Table 6 - Summary of performances of antenna by using different conductive materials

\begin{tabular}{|c|c|c|c|c|c|}
\hline \multirow{2}{*}{$\begin{array}{c}\text { Type of } \\
\text { Radiating } \\
\text { Elements } \\
\text { (Patch }\end{array}$} & \multicolumn{5}{|c|}{ Performances of antennas for different radiating elements } \\
\hline & & Return Loss $\left(\mathrm{S}_{11}\right)$ & $\begin{array}{l}\text { Bandwidth } \\
(\mathrm{GHz})\end{array}$ & $\begin{array}{l}\text { Gain } \\
\text { (dB) }\end{array}$ & $\begin{array}{c}\text { Efficiency } \\
(\%)\end{array}$ \\
\hline \multirow[t]{2}{*}{ Copper tape } & Simulation & $-39.51 \mathrm{~dB} @ 1.575 \mathrm{GHZ}$ & 0.073 & 2.06 & 34.21 \\
\hline & Measurement & $-20.71 \mathrm{~dB} @ 1.575 \mathrm{GHz}$ & 0.031 & 1.5 & 31.53 \\
\hline \multirow[t]{2}{*}{ SHIELDIT $^{\mathrm{TM}}$} & Simulation & $-45.29 \mathrm{~dB} @ 1.575 \mathrm{GHz}$ & 0.054 & 1.7 & 32.18 \\
\hline & Measurement & -14.97dB @1.575GHz & 0.02 & 1.23 & 29.03 \\
\hline \multirow[t]{2}{*}{ E-textile (1) } & Simulation & $-40.05 \mathrm{~dB} @ 1.575 \mathrm{GHz}$ & 0.073 & 1.4 & 30.25 \\
\hline & Measurement & $-27.09 \mathrm{~dB} @ 1.581 \mathrm{GHz}$ & 0.07 & 0.86 & 27.1 \\
\hline \multirow[t]{2}{*}{ E-textile (2) } & Simulation & $-48.11 \mathrm{~dB} @ 1.575 \mathrm{GHz}$ & 0.094 & 0.77 & 28.68 \\
\hline & Measurement & $-32.93 \mathrm{~dB} @ 1.566 \mathrm{GHz}$ & 0.068 & 0.61 & 25.95 \\
\hline
\end{tabular}

Fig. 9 shows the gain and radiation efficiency of all antenna samples. Based on this graph, electro-textile antenna gives acceptable performance with a gain value of more than $0 \mathrm{~dB}$ that is lower than the other two samples. This is due to the fact that the self-manufactured e-textile has the lowest conductivity $\left(3.02 \times 10^{4} \mathrm{~S} / \mathrm{m}\right)$, which has greatly affected the radiation efficiency of the antenna. Further analysis was done through simulation to verify the effects of low conductivity to the antenna performance, which is shown in Fig. 10. As predicted, as the conductivity gets lower, the transmission loss magnitude $S_{21}$ is higher which has resulted in more signals being loss in the device. Similarly, for return loss $S_{11}$, the performance is also degraded at lower conductivity range, which indicates that more reflection of signal could have happened.

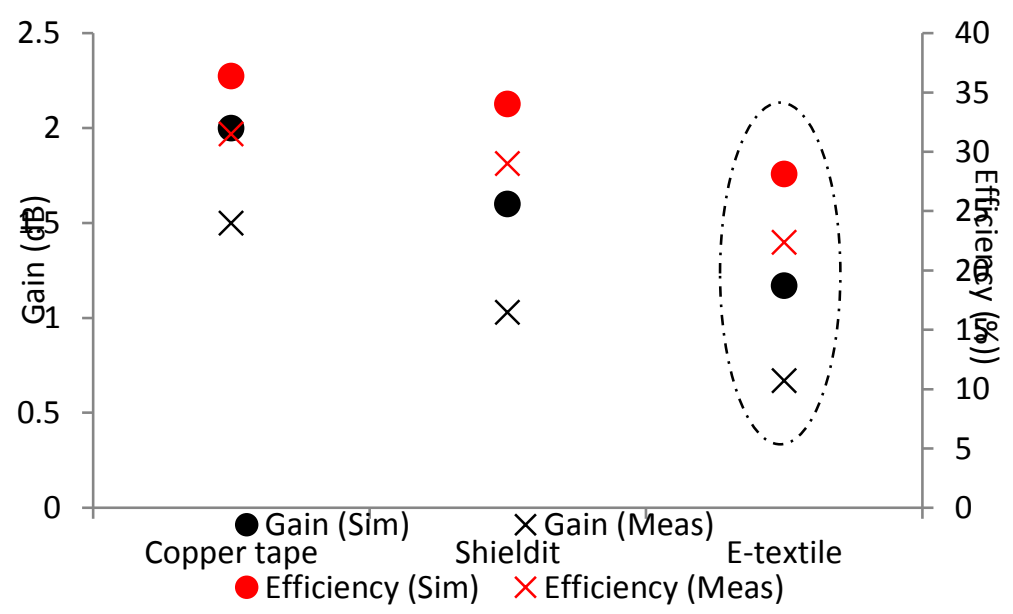

Fig. 9 - Graph showing the comparison of simulation and measurement of radiating elements to radiation efficiency and gain 


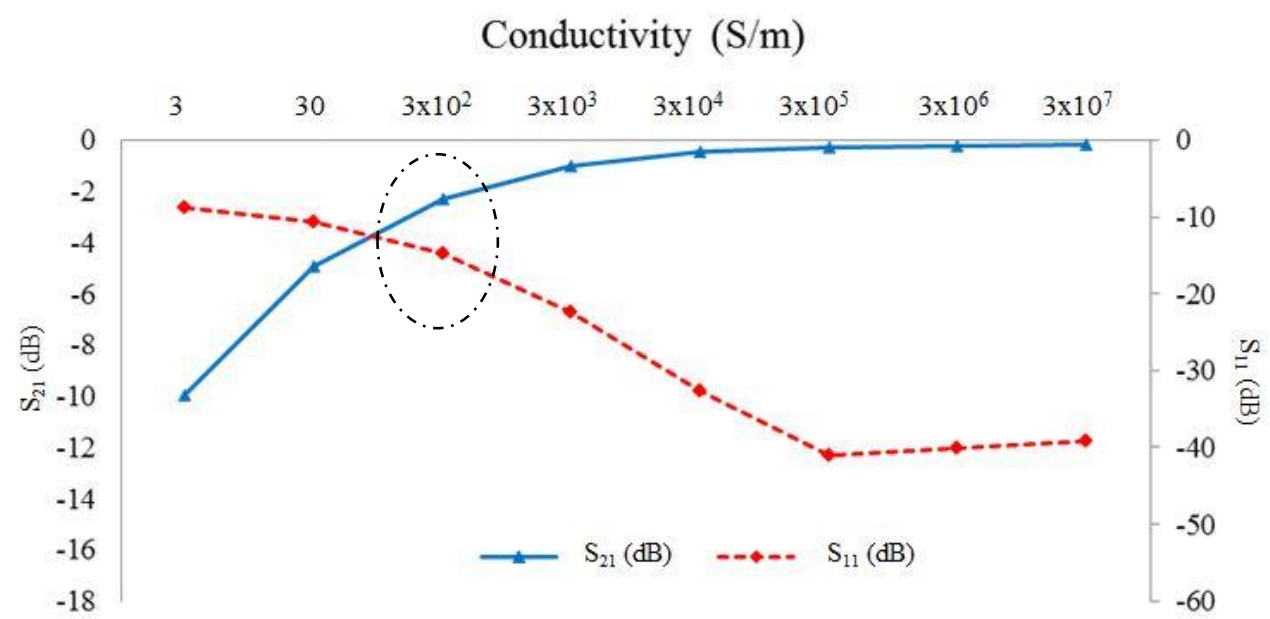

Fig. 10 - Graph showing the effecs of conductivity, to transmission loss $\left(\mathbf{S}_{21}\right)$; return loss $\left(\mathrm{S}_{11}\right)$

\section{Conclusion}

The performance obtained by the newly developed materials, SME-T had a reliable and acceptable achievement for textile antenna as there is a good agreement of gain and radiation efficiency value, besides the value of return loss, $S_{11}$ for SME-T antenna shown a good behavior. Further design optimizations are needed in this antenna to increase the gain and efficiency, such as by increasing the conductivity of the e-textile material (currently, $\sigma=\sim 10^{4}$ )Despite all the limitation, this SME-T antenna can still achieve good behavior, thus, the proof-of-concept of electro-textile as a radiating element and behave as a receiving antenna which requires low gain for passive monitoring was verified. This study is very useful for further analysis and design for wearable application.

\section{Acknowledgement}

Authors would like to thank all researchers of Antenna Research Centre, Faculty of Electrical Engineering, Universiti Teknologi MARA, Shah Alam, Selangor, Malaysia and Textile Research Group, Faculty of Applied Sciences, Universiti Teknologi MARA, Shah Alam, Selangor, Malaysia for supporting this project. This research was funded by Malaysia Ministry of Education through the Fundamental Research Grant Scheme (FRGS/1/2018/TK04/UITM/03/5).

\section{References}

[1] G. Christina, A. Rajeswari, M. Lavanya, J. Keerthana, K. Ilamathi, and V. Manoranjitha. (2016). Design and Development of Wearable Antennas for Tele-Medicine Applications, International Conference on Communication and Signal Processing, India, 2033-2037

[2] G. Monti, L. Tarricone, L. Corchia, and E. De Benedetto. (2016). Wearable logo-antenna for GPS-GSM-based tracking systems, IET Microwaves, Antennas Propag., 10, 1332-1338

[3] Z. H. Jiang, D. E. Brocker, P. E. Sieber, and D. H. Werner. (2014). A compact, low-profile metasurface-enabled antenna for wearable medical body-area network devices. IEEE Trans. Antennas Propag., 62, 4021-4030

[4] M. Abdullah and A. Khan. (2015). Multiband wearable textile antenna for I.S.M body center communication systems. Proc. Int. Semin. Direct Inverse Probl. Electromagn. Acoust. Wave Theory, DIPED, 90-96

[5] T. Björninen, J. Virkki, L. Sydänheimo, and L. Ukkonen. (2014). Impact of recurrent stretching on the performance of electro-textile UHF RFID tags, 5th Electron. Syst. Technol. Conf. ESTC 3-7

[6] S. B. Roshni, M. P. Jayakrishnan, P. Mohanan, and K. P. Surendran. (2017). Design and fabrication of an E-shaped wearable textile antenna on PVB-coated hydrophobic polyester fabric, Smart Mater. Struct., 26

[7] M. S. A. Nordin, N. H. A. Rahman, M. T. Ali, A. A. S. A. Shah, and M. R. Ahmad. (2018). Full-wave electromagnetic simulation of antenna on electro-textile and accurate measurement of dielectric properties through precise adjustable jig, Asia-Pacific Microw. Conf. Proceedings, APMC, 169-172

[8] N. H. Abd Rahman, Y. Yamada, and M. S. A. Nordin. (2018). Reliability of Strip Line Method for Determination of Conductivity for Lossy Conductive Materials, IEEE Access, 6, 64630-64638

[9] C. A. Balanis (2016). Antenna Theory: Analysis and Design (4th Ed.). Wiley 